\title{
LECITHIN LIPOSOMES AND MICROEMULSIONS AS NEW
}

CHROMATOGRAPHIC PHASES

3

4 Susana Amézqueta ${ }^{1, *}$, Alejandro Fernández-Pumarega ${ }^{1}$, Sandra Farré ${ }^{1}$, Daniel Luna ${ }^{1}$, Elisabet

$5 \quad$ Fuguet $^{1,2}$, Martí Rosés ${ }^{1}$

6

7

${ }^{1}$ Departament de Química Analítica and Institut de Biomedicina (IBUB), Facultat de Química,

8 Universitat de Barcelona, Martí i Franquès 1-11, 08028, Barcelona, Spain.

$9 \quad{ }^{2}$ Serra Húnter Programme. Generalitat de Catalunya. Spain

10

11

* Correspondence:

12

Susana Amézqueta Pérez

13

Departament de Química Analítica, Facultat de Química, Universitat de Barcelona

14

c/ Martí i Franquès 1-11, 08028, Barcelona, Spain

15

e-mail: samezqueta@ub.edu

16

Phone: (+34) 934021277

17

Fax: (+34) 934021233

18

19

Running title

20

Lecithin liposomes and microemulsions as new chromatographic phases

21

22 


\section{ABSTRACT}

Lecithins are phospholipidic mixtures that can be part of microemulsions and liposomes. In this work, ready-to-use preparations of lecithin have been tested as pseudostationary and mobile phases in EKC and LC, respectively. The selectivity of two EKC systems, one based on lecithin microemulsions (LMEEKC) and another on liposomes (LLEKC), and of a LC system based on lecithin microemulsions (MELC) has been evaluated through the solvation parameter model. In all cases, solute volume and hydrogen-bond basicity are the main descriptors that drive the partition process. While solute volume favors the retention of solutes, hydrogen-bond basicity has the contrary effect. In lecithin-based EKC systems the hydrogen-bond acidity of the solute leads to a higher retention while in the lecithin-based LC system a minor retention is produced. The three lecithin systems have been compared through the solvation parameter model to other chromatographic systems, most of them containing phospholipids. Principal component analysis reveals that lecithin systems cluster together with the other EKC systems based on phospholipids, with an immobilized artificial membrane (IAM) LC system, with the octanol/water reference partition system, and with a SDS-based microemulsion. Thus, they all show similar selectivity. However, the great advantage of using the ready-to use lecithin systems is that the laborious liposome preparation is avoided, and that their commercial availability makes them more affordable than IAM LC columns. Finally, taking into account that lecithin has a high semblance to the mammalian cell membranes composition, the ability of the three lecithin systems to mimic the pass of the solutes through the membranes has been evaluated. Experimental determinations have demonstrated that the skin partition of neutral solutes can be easily emulated, especially using the lecithinmicroemulsion EKC method. The model is robust and shows good prediction ability.

\section{KEYWORDS}

Solvation parameter model, physicochemical characterization, lecithin, surrogation, skin partition, chromatography 


\section{INTRODUCTION}

Capillary electrophoresis (CE) is a separation technique used in a wide number of applications that include either the determination of small compounds (pollutants, nutrients, drugs, biomarkers, etc.) and of large ones (enzymes, proteins, DNA, etc.). CE is also used for the physicochemical characterization of chemical substances ( $\mathrm{p} K_{\mathrm{a}}$ and $\log P_{\mathrm{o} / \mathrm{w}}$ determination); the evaluation of the interaction with other molecules such as the drug-protein binding; or the subrogation of biological properties of environmental or biomedical interest [1-3].

Microemulsion electrokinetic chromatography (MEEKC) and liposome electrokinetic chromatography (LEKC) are CE modalities that use a mobile phase containing a microemulsion or liposomes, respectively. Microemulsions are formed by surfactant-coated oil droplets, and usually a cosurfactant that acts as a stabilizer. Liposomes consist of a phospholipid bilayer with an encapsulated inner aqueous cavity. The surfactants or phospholipids used are charged and thus the microemulsion or the liposomes have their own electrophoretic mobility. In both cases, the solutes under analysis will migrate depending not only on their charge-to-size ratio (as in capillary zone electrophoresis (CZE)) but also on the partition with the corresponding pseudostationary phase (microemulsion or liposome) [4]. The partition is analogous to that in reversed-phase liquid chromatography (RPLC) and thus both techniques are considered CE-LC hybrids. Microemulsions can also be part of the mobile phase in reversed-phase chromatography and they give place to microemulsion liquid chromatography (MELC) [5]. As far as we are concerned, liposomes are not usually used as the mobile phase in LC. However, liposomes can be trapped in the pores of gel beads to generate immobilized liposome chromatography (ILC) or immobilized on the stationary phase to form an immobilized artificial membrane (IAM) [6,7].

Lecithins are mixtures of phospholipids (phosphatidylcholine, phosphatidylethanolamine, phosphatidylinositol, phosphatidylserine, etc.) that are extracted from different natural sources such as soy or egg. Commercial preparations based on lecithins are available to prepare emulsions and liposomes 
with cosmetic and pharmaceutical uses $\left(\right.$ Emulmetik $^{\mathrm{TM}}$, Pro-Lipo ${ }^{\mathrm{TM}}$, Lipoid $\left.^{\mathrm{TM}}\right)$. However, they have not been used yet to prepare chromatographic mobile phases. In the search of new chromatographic systems with different selectivity and taking into account the complexity when preparing a microemulsion or a liposome, it would be of great interest to investigate the viability of the ready-to-use commercial products as chromatographic phases and characterize their selectivity. In the present work we will evaluate the selectivity of a lecithin-based microemulsion in MEEKC (LMEEKC) and MELC (LMELC), and lecithin liposomes in LEKC (LLEKC). In LMEEKC and LLEKC lecithin acts as pseudostationary phase, and buffer as aqueous phase; inversely, in LMELC, C18 acts as stationary phase and lecithin as mobile phase.

The solvation parameter model (SPM) proposed by Abraham [8] is a popular quantitative structureproperty relationship (QSPR) model to characterize the selectivity of chromatographic systems $[9,10]$. The following equation is used to model the solvation that a neutral solute undergoes in a biphasic system and includes five different molecular descriptors.

$$
\log \mathrm{SP}=c+e E+s S+a A+b B+v V \quad[\text { Eq. 1] }
$$

Here, SP is the dependent solute property in a given partitioning system, i.e. equilibrium constant or some other free energy related property such as the chromatographic retention factor or a membrane partition. The $E, S, A, B$ and $V$ independent variables are the solute descriptors proposed by Abraham. $E$ represents the excess molar refraction, $S$ is the solute dipolarity/polarizability, $A$ and $B$ are the solute's effective hydrogen-bond acidity and hydrogen-bond basicity, respectively, and $V$ is McGowan's solute volume. The coefficients of the equation are characteristic of the biphasic system and reflect the difference of the two phases in properties complementary to the ones of solute descriptors. For any system, the coefficients of this equation can be obtained by multiple linear regression analysis between the $\log$ SP values acquired for an appropriate group of solutes and their descriptor values. Equations based on the SPM have been reported (some of them are shown in Table SI-1 of the Supplementary 
Material) to characterize several chromatographic systems. Similarly to the physicochemical systems ruled by partition, the literature proposes equations based on the SPM for different biological processes (Tables SI-2 and SI-3 of the Supplementary Material).

Characterizing two systems using the same model (the SPM in this work) makes them comparable, since similar partitioning systems will have similar coefficients [11]. Thus, after characterizing the three new systems with the SPM they will be compared with other physicochemical and biological systems. One parameter to compare their similarity we have proposed is the $d$ distance of the SPM coefficients [12]. The $d$ distance is calculated from the normalized coefficients of the two correlations to be compared. To do so, each system is considered as a five-dimensional vector of system coefficients $(e, s, a, b$, and $v)$, with a vector's length $(l)$ mathematically defined as:

$l=\sqrt{e^{2}+s^{2}+a^{2}+b^{2}+v^{2}}$,

and each system coefficient is divided by $l$ in order to obtain the normalized coefficients $\left(e_{u}, s_{u}, a_{u}, b_{u}\right.$, and $v_{u}$ ).

The $d$ parameter is the distance between the two normalized vectors, i.e.

$d=\sqrt{\left(e_{u 1}^{2}-e_{u 2}^{2}\right)+\left(s_{u 1}^{2}-s_{u 2}^{2}\right)+\left(a_{u 1}^{2}-a_{u 2}^{2}\right)+\left(b_{u 1}^{2}-b_{u 2}^{2}\right)+\left(v_{u 1}^{2}-v_{u 2}^{2}\right)}$

where the two subscripts 1 and 2 refer to the two systems to be compared. In previous works [13,14], a $d$ distance of 0.25 or less was stablished as adequate for surrogation. When many systems want to be compared, dendrograms of the $d$ distance and Principal Components Analysis (PCA) of the normalized coefficients can be used to identify the most similar systems. These approaches are based on simple and fast calculations and allow handling with a high number of data at once. They provide information about the similarity of the systems and are very adequate to compare the selectivity of two different physicochemical systems and to do a first selection of the physicochemical systems that can better 
emulate a biological property. Detailed information on these comparison tools is described elsewhere [19].

Once the most similar coefficients have been identified, the precision of the correlation between two of the systems (i.e. estimation of a biological parameter from a physicochemical one) can also be estimated from the errors of the biological and physicochemical system models and the systems dissimilarity [12,15-17]. Estimation from chromatographic measurements is usually performed through a linear equation of the type of Equation 4.

Here, $S P_{\text {bio }}$ is the solute biological property, $S P_{\text {chrom }}$ is the solute chromatographic property (in this case, the chromatographic or electrophoretic retention factor), and $q$ and $p$ are the ordinate and slope of the correlation, respectively.

In short, the expected precision of the correlation $\left(\mathrm{SD}_{\text {corr }}{ }^{2}\right)$ can be considered as the sum of three different contributions to the variance of the correlation: the biological data precision $\left(\mathrm{SD}_{\text {bio }}{ }^{2}\right)$, the chromatographic data precision $\left(p \times \mathrm{SD}_{\text {chrom }}\right)^{2}$ and the error due to the dissimilarity between the

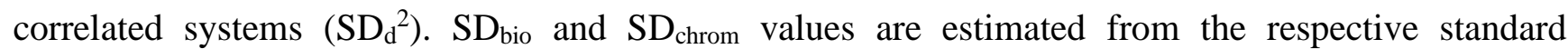
133 deviations of the SPM characterizations. In order to know $p$ and also $\mathrm{SD}_{d}^{2}$ the biological property and 134 the chromatographic property are calculated through their SPM equations and solutes' descriptors. In this way, $\mathrm{SD}_{\text {bio }}$ and $\mathrm{SD}_{\text {chrom }}$ are zero. The slope of the correlation of these calculated values provides $p$, and the SD of the correlation can be entirely attributed to the dissimilarity between both systems.

137 This kind of estimation is more laborious, so it is usually performed only for those pairs of systems that 138 show the highest similarity according to $d$ distances.

139 Those systems closer (with smallest $d$ or closest in the dendrogram and principal components space 140 plots) and with a good estimated correlation precision are identified as good candidates to surrogate each one the other system. In the case of physicochemical-biological pairs, the closest physicochemical 
system will probably be good surrogates for the biological system. To prove this, the physicochemical property (the retention factor in the chromatographic or the electrophoretic system) is measured and a correlation with the biological property is carried out for a series of representative compounds (Equation 4). If a good correlation is established between the properties of these two different systems, the biological property of a new chemical compound can be predicted by measuring the corresponding retention factor in the chromatographic system. The main advantage of this approach over QSPR studies is that it is not necessary to know the molecular descriptor values of the new compound such as in the SPM model. Furthermore, the use of chromatographic and electrophoretic measurements for prediction of biological properties is of main interest due the high level of automatization, speed of analysis, low cost, and high reproducibility of these techniques that lead to the ex vivo and in vivo tests avoidance. Due to the high structural and compositional similarity between mammalian cell membranes and lecithin-based microemulsions and liposomes it would be very interesting to test the possibility to mimic properties of environmental or biomedical concern using chromatographic measurements. In fact, lecithin-based chromatographic systems have already been used to mimic the intestinal absorption [18].

\section{MATERIAL AND METHODS}

\subsection{Equipment}

MELC measurements were done using a 10A series chromatograph from Shimadzu (Kyoto, Japan) equipped with a quaternary pump and a diode array detector and fitted with a Gemini C18 column (15 $\mathrm{cm} \times 4.6 \mathrm{~mm}$ i.d., $5 \mu \mathrm{m}$ particle size) (Phenomenex, Torrance, $\mathrm{CA}, \mathrm{US}$ ) preceded by the corresponding guard cartridge $(1 \mathrm{~cm})$.

MEEKC and LEKC measurements were done using the G1600A CE capillary electrophoresis system 
capillary $(30 \mathrm{~cm}$ effective length for MEEKC and $40 \mathrm{~cm}$ for LEKC, $38.5 \mathrm{~cm}$ total length for MEEKC and $48.5 \mathrm{~cm}$ for LEKC, $50 \mu \mathrm{m}$ i.d.) was obtained from Composite Metal Services Ltd (Shipley, UK).

\subsection{Reagents}

Methanol (HPLC-grade), hydrochloric acid (25\% in water), sodium hydroxide (>99\%), sodium dihydrogenphosphate monohydrate ( $>99 \%)$, disodium hydrogenphosphate $(>99 \%)$, and phenanthrene (>97\%) were from Merck (Darmstadt, Germany). Potassium bromide ( $\geq 99.5 \%)$, 1-butanol ( $\geq 99.7 \%$ ), heptane (99\%), and dodecanophenone (98\%) were from Sigma-Aldrich (St. Louis, MO, US). Water was purified by a Milli-Q plus system from Millipore (Bedford, MA, US), with a resistivity of $18.2 \mathrm{M} \Omega \mathrm{cm}$. The lecithin products to prepare the microemulsions and the liposomes were Emulmetik ${ }^{\mathrm{TM}} 300$ and ProLipo $^{\mathrm{TM}} \mathrm{Neo}$, respectively, from Lucas Meyer Cosmetics (Champlan, France). They were kindly supplied by Comercial Química Jover (Terrassa, Spain).

Tested substances were reagent grade or better and obtained from several manufacturers (Merck, SigmaAldrich, Carlo Erba (Milano, Italy), Baker (Center Valley, PA, US), Panreac (Castellar del Vallès, Spain), Thermo Fisher Scientific (Waltham, MA, US), and Scharlab).

\subsection{Microemulsion and liposomes preparation}

Lecithin microemulsions contained $0.5 \%$ (w/v) of lecithin and were prepared using Emulmetik ${ }^{\mathrm{TM}} 300$ as starting material, product that contains $97 \%$ of phospholipids. In the case of MEEKC, lecithin $(0.25$ g) was mixed with $35 \mathrm{~mL}$ of phosphate buffer $(20 \mathrm{mM}, \mathrm{pH} 7.0)$ in a magnetic stirrer at low speed (200 rpm). Next, 1-butanol (8.15\% (v/v)) was added drop by drop and the solution was stirred for 30 min. Then, heptane $(1.15 \%(\mathrm{v} / \mathrm{v}))$ was added and the suspension stirred for $30 \mathrm{~min}$ more. This suspension was transferred to a $50 \mathrm{~mL}$ volumetric flask and diluted with buffer. Finally, it was stirred for 1-2 h at low speed $(200 \mathrm{rpm})$ until the mixture turned semitransparent. In the case of MELC, a higher volume 
(0.5 L) was prepared using the proportional amounts of the reagents and stirring at higher speed (650

190

191

192

193

194

195

196

197

198

199

200

201

202

203

204

205

206

207 rpm).

Lecithin liposomes contained $0.5 \%(\mathrm{w} / \mathrm{v})$ of lecithin and were prepared using the preliposome ProLipo $^{\mathrm{TM}}$ Neo as starting material, product that contains around $20 \%$ of phospholipids. Preliposome $(0.5$ g) was mixed with $20 \mathrm{~mL}$ of buffer in a magnetic stirrer at high speed (1000 rpm) for $45 \mathrm{~min}$ at 25-30 ${ }^{\circ} \mathrm{C}$. The use of other brands of ready-to-use lecithin products to form microemulsions or liposomes should not provide very different results from those obtained in the present work. Notwithstanding, note that a new calibration curve has to be done for every batch-to-batch or brand-to-brand analysis.

\subsection{Preparation of the test compounds solutions}

For MELC, stock solutions (2000 mg/L) of the solutes and the hold-up time marker (potassium bromide) were prepared in methanol. Working solutions were prepared from stock solutions at a concentration of $50 \mathrm{mg} / \mathrm{L}$, solving the corresponding amount of stock solution in the microemulsion.

In the case of MEEKC, stock solutions of the solutes and the microemulsion marker (phenanthrene) (2000 mg/L) were prepared in methanol. Working solutions were prepared from the stock solutions and contained $400 \mathrm{mg} / \mathrm{L}$ of the solutes and $200 \mathrm{mg} / \mathrm{L}$ of the microemulstion marker. They were diluted to obtain a final methanol:buffer relation of 1:1. Methanol was used as the electroosmotic flow marker.

For LEKC, a stock solution containing the solutes (1000 mg/L) and the liposome marker (dodecanophenone) was prepared in methanol. Work solutions were prepared by direct dilution of the stock solution with buffer, and contained $200 \mathrm{mg} / \mathrm{L}$ of the solutes or the liposome marker. The final methanol:buffer relation was 1:4. Again methanol was used as the electroosmotic flow marker.

Finally, all solutions were passed through a $0.45 \mu \mathrm{m}$ nylon syringe filter obtained from Filter-Lab (Sant Pere de Riudebitlles, Spain).

\subsection{Analysis by LC}


Target compounds were analyzed using the microemulsion as mobile phase at $1 \mathrm{~mL} / \mathrm{min}$. The injection volume was $50 \mu \mathrm{L}$ and the column temperature $25^{\circ} \mathrm{C}$. After a preliminary scan, detection wavelengths were set at 200 and $254 \mathrm{~nm}$ depending on the compound absorption profile. All measurements were taken in triplicate. After analyses, the system was cleaned by passing through water for $60 \mathrm{~min}$, acetonitrile:water for $60 \mathrm{~min}$ and acetonitrile for $30 \mathrm{~min}$.

The LC retention factor $(k)$, was calculated according to Eq. 5.

$$
k=\frac{t_{R}-t_{0}}{t_{0}-t_{e}} \quad[\text { Eq. 5] }
$$

where $t_{R}$ corresponds to the solute retention time, $t_{0}$ is the column hold-up time, and $t_{e}$ is the extra column time determined by an analysis that excludes the chromatographic column. To measure $t_{e} a$ chromatographic correction with negligible hold-up volume has been used. $t_{0}$ and $t_{e}$ have been determined using an aqueous potassium bromide solution.

\subsection{Analysis by EKC}

Target compounds were analyzed using the microemulsion or the liposomes as pseudostationary phase.

Before the first use, the capillary was activated by the following washing sequence: water (5 min), $1 \mathrm{M}$ $\mathrm{NaOH}$ (20 min), water (2 min), 0.1 M NaOH (10 min), water (2 min) and microemulsion or liposome suspension (20 min). As daily conditioning, the capillary was flushed with water for 6 min, followed by methanol (3 min), water (3 min), $1 \mathrm{M} \mathrm{NaOH}$ (5 min), water (3 min), $0.1 \mathrm{M} \mathrm{NaOH}$ (3 min), water (1 min) and microemulsion or liposome suspension (5 min). Before each separation, the capillary was flushed with water $(2 \mathrm{~min})$, methanol $(2 \mathrm{~min})$, water $(1 \mathrm{~min}), 0.1 \mathrm{M} \mathrm{NaOH}(2 \mathrm{~min})$, water $(1 \mathrm{~min})$, and microemulsion or liposome suspension (4 min).

The injection was done during $3 \mathrm{~s}$ at $50 \mathrm{mbar}$, the capillary temperature was $25^{\circ} \mathrm{C}$, and the voltage was $+15 \mathrm{kV}$. After a preliminary scan, wavelengths were set at 200, 214, and $254 \mathrm{~nm}$ depending on the compound absorption profile. All measurements were done in triplicate. In terms of practicality, 
LMEEKC and LLEKC analytical procedures were similar, and both systems were robust in batch-tobatch analyses. Also, we did not detect run-to-run differences after applying the cleaning protocols described.

The retention factor $(k)$, was calculated according to Eq. 6 .

$$
k=\frac{t_{m}-t_{e o f}}{\left(1-\frac{t_{m}}{t_{p s}}\right) t_{e o f}}
$$

where $t_{m}$ is the solute migration time, $t_{\text {eof }}$ corresponds to the migration time of methanol, and $t_{\mathrm{ps}}$ is the migration time of the pseudostationary phase marker.

\subsection{Data analysis}

PCA and dendrogram plots were performed with Matlab package from MathWorks (Natick, MA, USA). Excel from Microsoft (Redmond, WA, US) was used for data calculations and multiple linear regression analyses. The Abraham descriptors of the substances were the same used in a previous study [19]. The biological data have been extracted from literature [20,21].

\section{RESULTS AND DISCUSSION}

\subsection{Characterization of the lecithin-based systems through the SPM model}

The retention factor of 59 solutes has been determined. These solutes were selected from a total of 71 set in a previous work [19] due to their variety of descriptors magnitude, their representability of the physicochemical space, and their compatibility with the lecithin systems. These solutes are neutral in the $\mathrm{pH}$ of work. Table 1 shows the set of compounds together with the retention factors obtained in the three chromatographic systems (an example of the chromatograms and electropherograms obtained is included in Figures 1-3 of the Supplementary Information). The results are an average of a minimum of 3 determinations and the RSD is under 5\%. Next, the logarithm of the retention factor determined in the 
corresponding chromatographic system has been correlated to the descriptors $A, B, S, E$ and $V$ of the solutes also presented in Table 1. Multiple linear regression between $\log k$ and the descriptors provide the coefficients and statistics for the physicochemical systems considered in the present work, which are shown in Table 2.

The systems are properly characterized by the SPM model: the determination coefficient $\left(\mathrm{R}^{2}\right)$ is higher than 0.90 in all cases, the standard error is low and in the order of that of other physicochemical systems characterized through this same model [19], $F_{c a l}$ value is much higher than $F_{\text {tab }}$ at a $95 \%$ confidence level, and all the SPM coefficients present statistical significance. Outliers, those compounds that present a residual value over $|2.5|$, non-detectable substances, and compounds that coeluted with the markers were not considered to set the model.

The direct comparison between the normalized coefficients of the SPM of each system (a graphical representation is shown in Figure 1) and the evaluation of the distance between these coefficients (Table 3) shows that the three lecithin based systems are very similar. The two electrophoretic systems (LMEEKC and LLEKC) are the most similar $\left(d_{\text {LMEEKC/LLEKC }}=0.15\right)$, whereas the chromatographic LMELC is slightly less similar $\left(d_{L M E L C / L M E E K C}=0.18, d_{\text {LMELC/LLEKC }}=0.20\right)$. The big similarity of LMELC to the two electrophoretic systems is somewhat surprising because in LMEEKC and LLEKC lecithin acts as pseudostationary phase and the aqueous buffer as mobile phase, but in LMELC C18 acts as stationary phase and lecithin as mobile phase. We speculate that due to its structure, lecithin probably has intermediate properties between the aqueous buffer and $\mathrm{C} 18$ and thus the partition C18/lecithin (LMELC) is similar in properties to the partition lecithin/water, being in any case C18 and water saturated with lecithin.

Solute volume $(V)$ and hydrogen-bond basicity $(B)$ present high coefficients for the three systems. The cavity contribution is more favorable to partition to the stationary or pseudostationary phase than to the mobile phase or to the buffer $(v>0)$, and the hydrogen-bond acidity of the stationary (C18) or pseudostationary phase (lecithin microemulsion and liposomes) is much lower, especially for the lecithin 
microemulsion, than that of the aqueous phase. All systems show a moderate negative polarizability value $(s)$, so the lecithin mobile phase is more polar than C18 stationary phase in LMELC, whereas lecithin pseudostationary phases are less polar than water in LMEEKC and LLECK especially in the latter system.

The liposomes system shows the highest $e$ value, which means that the liposomes are highly polarizable. The two electrophoretic systems show positive hydrogen-bond basicity value $(a)$, so they are more hydrogen-bond basic than the aqueous buffer, while the LMELC system presents a negative value, which means that lecithin microemulsion is more basic than the $\mathrm{C} 18$ stationary phase. Among other factors, the constant $(c)$ of the correlations is related to the phase ratio for the separation system, and this one depends on the microemulsion/liposome concentration and the molar volume of these suspensions [19].

\subsection{Comparison of the lecithin-based systems with other chromatographic systems}

The three lecithin-based systems (LMELC, LMEEKC, LLEKC) have been compared to other chromatographic systems included in Table 4. The selected systems use any of the three techniques of separation - MELC, MEEKC, LEKC - (SDS0.8, SDS1.6, Brij, and BrijSDS for MELC; SDSME for MEEKC; DGDCChol, DGDC, PAAU, and PSUA for LEKC), or contain phospholipids in the stationary phase (IAM, PLM) or in the pseudostationary phase (DHP, DHPChol and POPCPS), In addition, the octanol/water partition (OW) has been included as reference system in the evaluation of partition processes [22].

The similarity of these systems with the lecithin-based ones has been evaluated from the distance between the corresponding normalized SPM coefficients (Table 3). The systems that are more similar to the lecithin-based ones show a distance value under 0.25 units and are OW, SDSME, DHP, DHPChol, and all the systems formed by phospholipids (IAM, PLM, DGDC, DGDCChol, and POPCPS) independently of the technique used. The MELC systems that contain SDS in the mobile phase (SDS0.8, SDS1.6 and BrijSDS) show the biggest differences (in general, $d>0.45$ ). 
Figure 2 presents the dendrogram of $d$ distances, and the PCA of the normalized coefficients for all the selected chromatographic systems. Plots show three different clusters at $d=0.25$ level; the first one includes the lecithin-based systems (OW, SDSME, DHP, DHPChol, IAM, PLM, DGDC, DGDCChol, and POPCPS). The others include PSUA and PAAU (second cluster, polymeric-based LEKC systems); and SDS0.8, SDS1.6, Brij, BrijSDS (third cluster, surfactant-based MELC systems). Systems of the first cluster show negative PC1 and negative PC2. They differ from the third cluster mainly in the first principal component (PC1) and from the second cluster in the second principal component (PC2). The descriptors that have the main impact on PC1 are the solute's effective hydrogen-bond basicity $(B)$ and the McGowan's solute volume $(V)$. In PC2, all of the descriptors have some influence except for the McGowan's solute volume.

A relevant outcome is that all the systems containing phospholipids cluster together and are very similar to the reference OW, with independence of the chromatographic approach used. The lecithin-based LEKC system (LLEKC) behaves like the other LEKC systems based on phospholipids (DGDC, DHP, DHPChol and DGDCChol). It shows also high semblance to IAM, an immobilized artificial membrane of phospholipids used as stationary phase in RPLC. On the contrary, it shows different selectivity than the polymeric-based LEKC systems (PAAU and PSUA), probably due to the chemical difference between natural phospholipids and synthetic polymers. Generally, liposome preparation is laborious, time-consuming and it requires the characterization of the liposomes formed. The main advantage of using LLEKC over the other liposome systems is that the former is prepared by direct dilution of a readyto-use commercial product and does not imply a mandatory liposome characterization due to the simplicity of the preparation process. It is also more affordable than IAM columns.

In the case of MEEKC, the two systems evaluated (LMEEKC and SDSME) cluster together $(\mathrm{d}<0.25)$ and are different from the pure surfactant MELC systems (SDS0.8, SDS1.6, Brij, BrijSDS) that use C18 as stationary phase and form the second cluster. Probably, the contribution of the type of surfactant in the ME properties is negligible in favor of the presence of other components such as 1-butanol or 
heptane. Therefore, the partition is mainly influenced by the presence or absence of the C18 column. Despite the clustering of the two microemulsion EKC systems, LMEEKC and SDSME, they show some slight differences in selectivity. LMEEKC is more similar to LECK systems based on phospholipids, and to the phospholipid membrane LPS used as stationary phase in RPLC. Whereas, SDSME is more similar to LMELC. Surprisingly, LMELC system does not cluster with the surfactant-based MELC systems in the second cluster. A reason could be that lecithin in MELC is probably mostly adsorbed to the surface of the stationary phase and thus it is more similar to IAM (immobilized artificial membrane formed of phospholipids), PLM (phospholipid membrane) and SDSME (SDS microemulsion used as pseudostationary phase in EKC), also in the same cluster, than to surfactant-based MELC systems.

\subsection{Similarity of the lecithin-based systems and the biological systems}

Forty-two biological systems characterized through the SPM model have been considered in the present study (their SPM characterization is described in the Tables SI-2 and SI-3 of the Supplementary Material). They evaluate different properties of pharmaceutical interest related with the blood-tissue partition, permeation or absorption and others of environmental interest related to aquatic toxicity, cell permeation and soil absorption.

As before, the similarity of these systems with the lecithin-based ones has been evaluated through the $d$ distance parameter (Table 5). According to this criterion, the nineteen systems with the lowest $d$ distances have been selected. They include five and fourteen systems of pharmaceutical and environmental interest, respectively. A previous study used a lecithin-based system to predict intestinal absorption [18], however our predictions do not consider any of the three lecithin systems as candidates to model this parameter $(d \sim 0.85)$.

Next, the dendrogram of $d$ distances, and the PCA of the normalized coefficients of these nineteen systems have been plotted (Figure 3). These plots show that the biological systems that are closer, and hence show similar characteristics to the lecithin ones, are toxicity to rana tadpoles and blood brain 
barrier permeability estimated by the parallel artificial membrane permeability assay (PAMPA) in the case of LLEKC and LMELC, and skin partition, blood-lung partition, and toxicity to several aquatic species in the case of LMEEKC. In concrete and according to both the distance and the clustering criteria, the biological systems that probably will be best emulated by the lecithin systems are toxicity to tadpoles and skin partition. Our group of research has recently reported a method using MEKC to surrogate the toxicity to tadpoles [13] and other species [23] and a method using RPLC to surrogate skin partition [24]. The RPLC method uses a C18 stationary phase and $10 \mathrm{mM}$ phosphate buffer (pH 7) : acetonitrile 60:40 as mobile phase and requires two descriptors to model the property, the retention factor in the chromatographic system and the McGowan volume of the solute. Thus now we will test the possibility to emulate the skin partition $\left(\log \mathrm{K}_{\mathrm{SC}}\right)$ using a direct method that only requires the retention factor determination, and more ecofriendly analyses that do not use high volume of organic solvents.

To this end, the variance of the final correlation $\left(\mathrm{SD}_{\text {corr }}\right.$ cal $\left.^{2}\right)$ between skin partition and the physicochemical property data (the retention factor) of the selected systems has been estimated. Results are shown in Table 6 . The $\mathrm{SD}_{\text {corr cal }}{ }^{2}$ value is very low and little variance is added due to the dissimilarity between compared systems $\left(\mathrm{SD}_{\mathrm{d}}{ }^{2}\right)$. Thus, skin partition is a promising system to be surrogated by the three lecithin-based systems, probably best by LMEEKC and LLEKC, which show low dissimilarity with the biological system and the lowest $\mathrm{SD}_{\mathrm{d}}^{2}$ and $\mathrm{SD}_{\text {corr cal }}{ }^{2}$ values. This fact, together with the higher complexity in the preparation of high volumes of microemulsion, and the intensive cleaning protocols needed when working with microemulsions in LC systems have led to the suppression of the LMELC system as candidate for the surrogation. As indicated in Section 2.6, LMEEKC and LLEKC did not show big differences in terms of practicality. Therefore, the ability of the LMEEKC and LLEKC systems to surrogate the skin partition of neutral solutes has been evaluated.

\subsection{Evaluation of the performance of lecithin systems to estimate skin partition}


To evaluate the skin partition the retention factor of the solutes included in Table 1 with known skin partition values $\left(\mathrm{K}_{\mathrm{SC}}\right)$ [21] has been determined (Eq. 3) by LLEKC and LMEEKC. Also other compounds with known $\mathrm{K}_{\mathrm{SC}}$ values have been incorporated into the analysis to get more statistical significance in the further skin partition estimation study (Table 7). They present different $\mathrm{K}_{\mathrm{SC}}$ values [21], physicochemical representability and detectability in the UV-Vis, and are neutral at the working $\mathrm{pH}$. Then, a regression analysis between the biological property logarithm values and the retention factor logarithm values ( $k_{\text {LLEKC }}$ and $k_{\text {LMEEKC }}$ for LLEKC and LMEEKC systems, respectively) has been done according to Eq. 4. Eq. 7 and Eq. 8 include the regression parameters and the statistics for LEKC and MEEKC, respectively. $S D_{\text {correl }}^{2}$ stands for the variance of the correlation $\log \mathrm{K}_{\mathrm{SC}} v s \log k$.

$$
\begin{gathered}
\log K_{S C}=1.24(0.08)+0.59(0.05) \log k_{\text {LLEKC }} \quad\left(S D_{\text {correl }}^{2}=0.089 ; n=21(2 \text { outliers }) ; R^{2}=\right. \\
0.671 ; F=39) \quad \text { [Eq. } 7]
\end{gathered}
$$

$$
\log K_{S C}=1.29(0.06)+0.71(0.08) \log k_{\text {LMEEKC }} \quad\left(S D_{\text {correl }}^{2}=0.050 ; n=24 ; R^{2}=0.789 ; F=\right.
$$

82) [Eq. 8]

As expected considering the initial predictions, it has been possible to surrogate skin partition directly from the retention of the solute in the chromatographic system. Significant coefficients and good statistical parameters (determination coefficient over 0.60, standard deviation in the order of the biological data, significant $\mathrm{F}$ value) have also been obtained. In accordance with the clustering in Figure 3, all statistics are slightly better for the LMEEKC system. Furthermore, the number of solutes considered is higher and it does not contain outliers. Therefore, we have selected the LMEEKC system as best candidate to model the skin partition of the solutes. Figure 4 shows the graphical representation of the regression of $\log \mathrm{K}_{\mathrm{SC}} \mathrm{vs} \log k_{\mathrm{LMEEKC}}$.

The LMEEKC system has been validated to prove its robustness and ability to predict skin partition following the method proposed previously [25]. To perform the model's validation, the set of solutes (24 compounds) has been divided into a training set (15 compounds, around $2 / 3$ of the compounds) and 
a test set (9 compounds, around 1/3 of the compounds). This selection has been done considering the solutes distribution in a PCA plotted using the SPM descriptors that represents the chemical space. In this way, compounds are distributed in the scores plot according to their physicochemical properties, and a representative selection of compounds of different nature has been done for both, the training set and the test set. For the internal validation, the model is established again, but only with the solutes of the training set.

$$
\begin{gathered}
\log K_{S C}=1.33(0.08)+0.77(0.10) \log k_{L M E E K C} \quad\left(S D_{\text {correl }}^{2}=0.052 ; n=15 ; R^{2}=0.828 ; F=\right. \\
\left.63 ; Q_{L M O}^{2}=0.98\right) \quad[\text { Eq. 9] }
\end{gathered}
$$

Eq. 9 shows the correlation parameters obtained. Equations' coefficients are similar to those of the model with all solutes (Eq. 8), which is indicative of the robustness of the model. Adequate determination coefficient, standard deviation, F value, and leave-multiple-out cross-validation coefficient (over 0.90) have also been obtained.

Finally, the external validation has been carried out. A regression between the experimental skin partition parameter and the one predicted through the training set equation has been done for the compounds of the test set (Eq. 10). According to statistics, the model considered shows good prediction ability: the slope of the trend line is not significantly different from unity and the intercept from zero at $95 \%$ confidence level by the Students t-test; the variance $\left(\mathrm{SD}^{2}\right)$ is of the same order of that of the biological data $\left(\mathrm{SD}^{2}=0.047\right)$, the determination coefficient $\left(\mathrm{R}^{2}\right)$ is above 0.70 ; the correlation cross-validation coefficient $\left(\mathrm{QLMO}^{2}\right)$ is above 0.6; and the Fisher's F parameter is significant.

$$
\log K_{S C, \text { predicted }}=0.12(0.25)+0.93(0.23) \log K_{S C, \text { experimental }} \quad\left(S D_{\text {correl }}^{2}=0.063 ; n=\right.
$$

$$
\text { 9; } \left.R^{2}=0.711 ; F=17 ; Q_{L M O}^{2}=0.66\right)
$$

\section{CONCLUSION}

Three different chromatographic systems based on lecithin have been characterized through the SPM model. They are quite similar regarding the interaction with neutral compounds, and the main driving 
436 forces implied are hydrophobicity and the hydrogen-bond acidity of the systems. The main differences 437 between them lie in the hydrogen-bond basicity and polarizability. They also show very similar partition 438 physicochemical characteristics to other phospholipid-based chromatographic systems, while they offer 439 more easy preparation and availability because they are based on ready-to-use commercial products. 440 Chemometric evaluation has shown that all three are good candidates to model skin partition of 441 compounds, especially that of LMEEKC. Moreover, EKC systems are more practical in terms of technical issues compared to the LC one. Experimental evaluation has confirmed that the electrokinetic system based on lecithin microemulsions (LMEEKC) is able to model skin partition through a direct correlation between the logarithms of the chromatographic retention factor and the skin partition parameter. Therefore, it offers an alternative to skin in vivo or tissue in vitro testing.

\section{ACKNOWLEDGEMENTS}

This article is dedicated to Professor Colin F. Poole to commemorate his $70^{\text {th }}$ birthday. We acknowledge his guidance in chromatography during all these years.

Financial support from the Ministerio de Economía y Competitividad from the Spanish Government (CTQ2017-88179-P) and the Catalan Government (2017SGR1074) is acknowledged. AFP wishes to thank the University of Barcelona for his APIF PhD fellowship. Thanks are given to Comercial Química Jover (Terrassa, Spain) for providing the lecithin Emulmetik ${ }^{\mathrm{TM}} 300$ and Pro-Lipo ${ }^{\mathrm{TM}}$ Neo products.

\section{CONFLICT OF INTEREST}

458 The authors declare no competing financial interest. 


\section{REFERENCES}

[1] S. El Deeb, H. Wätzig, D. Abd El-Hady, C. Sänger-van de Griend, G.K.E. Scriba, Recent advances in capillary electrophoretic migration techniques for pharmaceutical analysis (20132015), Electrophoresis. 37 (2016) 1591-1608. doi:10.1002/elps.201600058.

[2] C.F. Poole, A.D. Gunatilleka, S.K. Poole, In search of a chromatographic model for biopartitioning, Adv. Chromatogr. 40 (1999) 159-229.

[3] D.M. Cimpean, C.F. Poole, Systematic search for surrogate chromatographic models of biopartitioning processes, Analyst. 127 (2002) 724-729.

[4] S.K. Wiedmer, J. Lokajová, M.L. Riekkola, Marker compounds for the determination of retention factors in EKC, J. Sep. Sci. 33 (2010) 394-409. doi:10.1002/jssc.200900625.

[5] A. Marsh, B.J. Clark, K.D. Altria, A review of the background, operating parameters and applications of microemulsion liquid chromatography (MELC), J. Sep. Sci. 28 (2005) 20232032. doi:10.1002/jssc.200500129.

[6] F. Tsopelas, T. Vallianatou, A. Tsantili-Kakoulidou, Advances in immobilized artificial membrane (IAM) chromatography for novel drug discovery, Expert Opin. Drug Discov. 11 (2016) 473-488. doi:10.1517/17460441.2016.1160886.

[7] C. Lepont, C.F. Poole, Retention characteristics of an immobilized artificial membrane column in reversed-phase liquid chromatography, J. Chromatogr. A. 946 (2002) 107-124. doi:10.1016/S0021-9673(01)01579-5.

[8] M.H. Abraham, Scales of solute hydrogen-bonding: their construction and application to physicochemical and biochemical processes, Chem. Soc. Rev. 22 (1993) 73. doi:10.1039/cs9932200073.

[9] C.F. Poole, Selectivity characterization of pseudostationary phases using the solvation 
parameter model, in: U. Pyell (Ed.), Electrokinet. Chromatogr. Theory, Instrum. Appl., First, Wiley, Chichester, 2007: pp. 55-78.

[10] C.F. Poole, S.K. Poole, Column selectivity from the perspective of the solvation parameter model, J. Chromatogr. A. 965 (2002) 263-299. doi:10.1016/S0021-9673(01)01361-9.

[11] C.F. Poole, T.C. Ariyasena, N. Lenca, Estimation of the environmental properties of compounds from chromatographic measurements and the solvation parameter model., J. Chromatogr. A. 1317 (2013) 85-104. doi:10.1016/j.chroma.2013.05.045.

[12] E. Lázaro, C. Ràfols, M.H. Abraham, M. Rosés, Chromatographic estimation of drug disposition properties by means of immobilized artificial membranes (IAM) and C18 columns, J. Med. Chem. 49 (2006) 4861-4870. doi:10.1021/jm0602108.

[13] A. Fernández-Pumarega, S. Amézqueta, E. Fuguet, M. Rosés, Tadpole toxicity prediction using chromatographic systems, J. Chromatogr. A. 1418 (2015). doi:10.1016/j.chroma.2015.09.056.

[14] M. Hidalgo-Rodríguez, E. Fuguet, C. Ràfols, M. Rosés, Modeling nonspecific toxicity of organic compounds to the fathead minnow fish by means of chromatographic systems, Anal. Chem. 84 (2012) 3446-3452. doi:10.1021/ac2034453.

[15] E. Fuguet, C. Ràfols, E. Bosch, M.H. Abraham, M. Rosés, Selectivity of single, mixed, and modified pseudostationary phases in electrokinetic chromatography, Electrophoresis. 27 (2006) 1900-1914. doi:10.1002/elps.200500464.

[16] J.A. Castillo-Garit, Y. Marrero-Ponce, J. Escobar, F. Torrens, R. Rotondo, A novel approach to predict aquatic toxicity from molecular structure, Chemosphere. 73 (2008) 415-427. doi:10.1016/j.chemosphere.2008.05.024.

[17] M. Hidalgo-Rodríguez, E. Fuguet, C. Ràfols, M. Rosés, Estimation of biological properties by means of chromatographic systems: Evaluation of the factors that contribute to the variance of 
biological-chromatographic correlations, Anal. Chem. 82 (2010) 10236-10245. doi:10.1021/ac102626u.

[18] X.Y. Liu, C. Nakamura, Q. Yang, N. Kamo, J. Miyake, Immobilized liposome chromatography to study drug-membrane interactions: Correlation with drug absorption in humans, J. Chromatogr. A. 961 (2002) 113-118. doi:10.1016/S0021-9673(02)00505-8.

[19] E. Fuguet, C. Ràfols, E. Bosch, M.H. Abraham, M. Rosés, Solute-solvent interactions in micellar electrokinetic chromatography: III. Characterization of the selectivity of micellar electrokinetic chromatography systems, J. Chromatogr. A. 942 (2002) 237-248. doi:10.1016/S0021-9673(01)01383-8.

[20] M.H. Abraham, F. Martins, Human skin permeation and partition: General linear free-enegy relationship analyses, J. Pharm. Sci. 93 (2004) 1508-1523.

[21] L. Wang, L. Chen, G. Lian, L. Han, Determination of partition and binding properties of solutes to stratum corneum, Int. J. Pharm. 398 (2010) 114-122. doi:10.1016/j.ijpharm.2010.07.035.

[22] C.F. Poole, N. Lenca, Applications of the solvation parameter model in reversed-phase liquid chromatography, J. Chromatogr. A. 1486 (2017) 2-19. doi:10.1016/j.chroma.2016.05.099.

[23] A. Fernández-Pumarega, S. Amézqueta, S. Farré, L. Muñoz-Pascual, M.H. Abraham, E. Fuguet, et al., Modeling Aquatic Toxicity through Chromatographic Systems, Anal. Chem. 89 (2017) 7996-8003. doi:10.1021/acs.analchem.7b01301.

[24] M. Hidalgo-Rodríguez, S. Soriano-Meseguer, E. Fuguet, C. Ràfols, M. Rosés, Evaluation of the suitability of chromatographic systems to predict human skin permeation of neutral compounds, Eur. J. Pharm. Sci. 50 (2013) 557-568. doi:10.1016/j.ejps.2013.04.005.

[25] K. Roy, On some aspects of validation of predictive quantitative structure-activity relationship models, Expert Opin. Drug Discov. 2 (2007) 1567-1577. doi:10.1517/17460441.2.12.1567. 
530

531 


\section{Table 1}

534 SPM descriptors and logarithm of the retention factor of the solutes used to characterize the LMELC,

535 LMEEKC and LLEKC systems based on lecithin

\begin{tabular}{|c|c|c|c|c|c|c|c|c|}
\hline & E & $S$ & $A$ & $B$ & $V$ & $\log k_{\text {LMELC }}$ & $\log k_{\text {LMEEKC }}$ & $\log k_{\text {LLEKC }}$ \\
\hline 1,2,3-Trihydroxybenzene & 1.165 & 1.350 & 1.350 & 0.620 & 0.8925 & -0.37 & -1.16 & -0.68 \\
\hline 2,3-Benzofuran & 0.888 & 0.830 & 0.000 & 0.150 & 0.9053 & 1.89 & 0.14 & 0.44 \\
\hline 2,3-Dimethylphenol & 0.850 & 0.850 & 0.520 & 0.360 & 1.0569 & - & -0.20 & 0.29 \\
\hline 2,4-Dimethylphenol & 0.843 & 0.800 & 0.530 & 0.390 & 1.0569 & - & -0.23 & 0.31 \\
\hline 2-Naphthol & 1.520 & 1.080 & 0.610 & 0.400 & 1.1441 & 1.67 & 0.30 & 0.73 \\
\hline 2-Nitroaniline & 1.180 & 1.370 & 0.300 & 0.360 & 0.9904 & 1.20 & -0.58 & -0.08 \\
\hline 2-Nitroanisole & 0.968 & 1.340 & 0.000 & 0.450 & 1.0902 & 1.20 & -0.72 & -0.25 \\
\hline 3-Chloroaniline & 1.053 & 1.100 & 0.300 & 0.300 & 0.9386 & 1.35 & -0.37 & 0.00 \\
\hline 3-Methylphenol & 0.822 & 0.880 & 0.570 & 0.340 & 0.9160 & 1.28 & -0.56 & -0.20 \\
\hline 3-Nitroaniline & 1.200 & 1.710 & 0.400 & 0.350 & 0.9904 & 1.00 & -0.73 & -0.27 \\
\hline 4-Aminobenzamide & 1.340 & 1.940 & 0.800 & 0.940 & 1.0726 & 0.02 & -1.30 & -1.18 \\
\hline 4-Chloroacetanilide & 0.980 & 1.470 & 0.640 & 0.510 & 1.2361 & 1.33 & -0.45 & -0.06 \\
\hline 4-Chloroaniline & 1.060 & 1.130 & 0.300 & 0.310 & 0.9386 & 1.32 & -0.38 & -0.06 \\
\hline 4-Chlorophenol & 0.915 & 1.080 & 0.670 & 0.200 & 0.8975 & 1.56 & -0.04 & 0.10 \\
\hline 4-Nitroaniline & 1.220 & 1.930 & 0.460 & 0.350 & 0.9904 & 0.95 & -0.75 & -0.23 \\
\hline Acetanilide & 0.900 & 1.390 & 0.480 & 0.670 & 1.1137 & 0.65 & -1.25 & -0.93 \\
\hline Acetophenone & 0.818 & 1.010 & 0.000 & 0.480 & 1.0139 & 1.16 & -0.94 & -0.73 \\
\hline Aniline & 0.955 & 0.960 & 0.260 & 0.410 & 0.8162 & 0.66 & -1.22 & -0.92 \\
\hline Anisole & 0.708 & 0.750 & 0.000 & 0.290 & 0.9160 & 1.61 & -0.41 & -0.15 \\
\hline Antipyrine & 1.320 & 1.500 & 0.000 & 1.480 & 1.4846 & 0.17 & - & -1.61 \\
\hline$\alpha$-Pinene & 0.446 & 0.140 & 0.000 & 0.120 & 1.2574 & 1.23 & - & 0.44 \\
\hline Benzaldehyde & 0.820 & 1.000 & 0.000 & 0.390 & 0.8730 & 1.08 & 0.76 & -0.76 \\
\hline Benzamide & 0.990 & 1.500 & 0.490 & 0.670 & 0.9728 & 0.42 & - & -1.10 \\
\hline Benzene & 0.610 & 0.520 & 0.000 & 0.140 & 0.7164 & 1.19 & -0.41 & -0.10 \\
\hline Benzyl benzoate & 1.264 & 1.420 & 0.000 & 0.510 & 1.6804 & - & 1.17 & - \\
\hline Methyl benzoate & 0.733 & 0.850 & 0.000 & 0.460 & 1.0726 & 1.56 & -0.46 & -0.20 \\
\hline Benzophenone & 1.447 & 1.500 & 0.000 & 0.500 & 1.4808 & 2.00 & 0.40 & 0.83 \\
\hline Benzonitrile & 0.742 & 1.110 & 0.000 & 0.330 & 0.8711 & 1.13 & -0.94 & -0.66 \\
\hline Bromobenzene & 0.882 & 0.730 & 0.000 & 0.090 & 0.8914 & 1.86 & 0.43 & 0.58 \\
\hline Butyrophenone & 0.797 & 0.950 & 0.000 & 0.510 & 1.2957 & - & -0.08 & 0.23 \\
\hline Caffeine & 1.500 & 1.720 & 0.050 & 1.280 & 1.3632 & 0.04 & - & - \\
\hline
\end{tabular}




\begin{tabular}{ccccccccc} 
Catechol & 0.970 & 1.100 & 0.880 & 0.470 & 0.8338 & 0.65 & -1.04 & -0.56 \\
Chlorobenzene & 0.718 & 0.650 & 0.000 & 0.070 & 0.8388 & - & 0.26 & 0.46 \\
Corticosterone & 1.860 & 3.430 & 0.400 & 1.630 & 2.7389 & 1.21 & -0.61 & 0.10 \\
Cortisone & 1.960 & 3.500 & 0.360 & 1.870 & 2.7546 & 0.84 & -1.02 & -0.38 \\
Estradiol & 1.800 & 1.770 & 0.860 & 1.100 & 2.1988 & 1.17 & 0.37 & - \\
Estratriol & 1.970 & 1.740 & 1.060 & 1.630 & 2.2575 & - & -0.74 & - \\
Ethylbenzene & 0.613 & 0.510 & 0.000 & 0.150 & 0.9982 & - & 0.53 & 0.83 \\
Phenol & 0.805 & 0.890 & 0.600 & 0.300 & 0.7751 & 0.95 & -0.92 & -0.51 \\
Furan & 0.369 & 0.510 & 0.000 & 0.130 & 0.5363 & -0.47 & - & - \\
Geraniol & 0.513 & 0.630 & 0.390 & 0.660 & 1.4903 & - & 0.19 & 0.36 \\
Heptanophenone & 0.720 & 0.950 & 0.000 & 0.500 & 1.7184 & - & 1.56 & 1.64 \\
Hydrocortisone & 2.030 & 3.490 & 0.710 & 1.900 & 2.7976 & 0.91 & -0.90 & -0.31 \\
Hydroquinone & 1.063 & 1.270 & 1.060 & 0.570 & 0.8338 & 0.31 & - & - \\
Monuron & 1.140 & 1.500 & 0.470 & 0.780 & 1.4768 & 1.20 & -0.78 & -0.46 \\
Naphthalene & 1.340 & 0.920 & 0.000 & 0.200 & 1.0854 & 2.05 & 0.82 & 1.09 \\
Nitrobenzene & 0.871 & 1.110 & 0.000 & 0.280 & 0.8906 & 1.37 & -0.61 & -0.27 \\
o-Toluidine & 0.966 & 0.920 & 0.230 & 0.450 & 0.9571 & 0.94 & -0.98 & -0.75 \\
Pyrimidine & 0.606 & 0.930 & 0.000 & 0.670 & 0.6342 & 0.03 & - & - \\
Pyrrole & 0.613 & 0.910 & 0.220 & 0.250 & 0.5774 & -0.03 & - & -1.09 \\
Propylbenzene & 0.604 & 0.500 & 0.000 & 0.150 & 1.1391 & 1.24 & 1.07 & -0.14 \\
Propiophenone & 0.804 & 0.950 & 0.000 & 0.510 & 1.1548 & 1.56 & -0.51 & -0.22 \\
p-Xylene & 0.613 & 0.520 & 0.000 & 0.160 & 0.9982 & - & 0.57 & 0.74 \\
Quinoline & 1.268 & 0.970 & 0.000 & 0.540 & 1.0443 & 1.37 & -0.81 & -0.55 \\
Resorcinol & 0.980 & 1.110 & 1.090 & 0.520 & 0.8338 & 0.52 & -1.11 & -0.56 \\
Thymol & 0.822 & 0.790 & 0.520 & 0.440 & 1.3387 & 1.92 & 0.44 & 0.91 \\
Thiourea & 0.840 & 0.820 & 0.770 & 0.870 & 0.5696 & -0.03 & - & - \\
Toluene & 0.601 & 0.520 & 0.000 & 0.140 & 0.8573 & - & 0.08 & 0.36 \\
Valerophenone & 0.795 & 0.950 & 0.000 & 0.500 & 1.4366 & 2.07 & 0.42 & 0.55 \\
\hline & & & & & & & & - \\
Pan
\end{tabular}

536 
Table 2

542 Coefficients and statistics of the SPM model for the systems based on lecithin

543

\begin{tabular}{|c|c|c|c|c|c|c|c|c|c|c|c|c|c|c|c|c|}
\hline & \multicolumn{6}{|c|}{ LSER coefficients } & \multicolumn{5}{|c|}{ Normalized LSER coefficients } & \multicolumn{5}{|c|}{ Statistics } \\
\hline & $\begin{array}{c}c \\
\left(\mathrm{SD}_{\mathrm{c}}\right)\end{array}$ & $\begin{array}{c}e \\
\left(\mathrm{SD}_{\mathrm{e}}\right)\end{array}$ & $\begin{array}{c}s \\
\left(\mathrm{SD}_{\mathrm{s}}\right)\end{array}$ & $\begin{array}{c}a \\
\left(\mathrm{SD}_{\mathrm{a}}\right)\end{array}$ & $\begin{array}{c}b \\
\left(\mathrm{SD}_{\mathrm{b}}\right)\end{array}$ & $\begin{array}{c}v \\
\left(\mathrm{SD}_{\mathrm{v}}\right)\end{array}$ & $e_{u}$ & $s_{u}$ & $a_{u}$ & $b_{u}$ & $v_{u}$ & $\mathrm{n}$ & $\mathrm{R}^{2}$ & SD & $\mathrm{F}$ & $\mathrm{n}_{\text {outliers }}$ \\
\hline LMELC & $\begin{array}{c}0.525 \\
(0.046)\end{array}$ & $\begin{array}{c}0.250 \\
(0.067)\end{array}$ & $\begin{array}{c}-0.591 \\
(0.039)\end{array}$ & $\begin{array}{l}-0.212 \\
(0.039)\end{array}$ & $\begin{array}{l}-1.984 \\
(0.059)\end{array}$ & $\begin{array}{c}2.084 \\
(0.059)\end{array}$ & 0.085 & -0.200 & -0.072 & -0.671 & 0.705 & 39 & 0.984 & 0.078 & 410 & $9^{a}$ \\
\hline LMEEKC & $\begin{array}{c}-2.217 \\
(0.098)\end{array}$ & $\begin{array}{c}0.431 \\
(0.104)\end{array}$ & $\begin{array}{c}-0.624 \\
(0.067)\end{array}$ & $\begin{array}{c}0.330 \\
(0.074)\end{array}$ & $\begin{array}{l}-3.709 \\
(0.161)\end{array}$ & $\begin{array}{c}3.317 \\
(0.115)\end{array}$ & 0.085 & -0.124 & 0.065 & -0.735 & 0.658 & 47 & 0.937 & 0.131 & 246 & $3^{\mathrm{b}}$ \\
\hline LLEKC & $\begin{array}{l}-1.869 \\
(0.083)\end{array}$ & $\begin{array}{c}0.885 \\
(0.118)\end{array}$ & $\begin{array}{c}-0.809 \\
(0.078)\end{array}$ & $\begin{array}{c}0.339 \\
(0.065)\end{array}$ & $\begin{array}{l}-2.865 \\
(0.112)\end{array}$ & $\begin{array}{c}2.809 \\
(0.092)\end{array}$ & 0.211 & -0.193 & 0.081 & -0.682 & 0.669 & 46 & 0.968 & 0.125 & 241 & $5^{\mathrm{c}}$ \\
\hline
\end{tabular}

544

${ }^{a}$ Furan, $\alpha$-pinene, pyrogallol (1,2,3-trihydroxybenzene), pyrrole, propylbenzene, thiourea, aniline, benzene, $o$-toluidine; ${ }^{\mathrm{b}}$ Benzaldehyde, 4 -

aminobenzamide, $\beta$-estradiol; ${ }^{c}$ propylbenzene, $\alpha$-pinene, monuron, quinolone, 4 -aminobenzamide 
$549 d$ distance values between lecithin-based and other physicochemical systems, according to the SPM 550 coefficients comparison. Values under 0.25 are in bold format

551

\begin{tabular}{cccc} 
System & LMELC & LMEEKC & LLEKC \\
\hline LMELC & -- & $\mathbf{0 . 1 8}$ & $\mathbf{0 . 2 0}$ \\
LMEEKC & $\mathbf{0 . 1 8}$ & -- & $\mathbf{0 . 1 5}$ \\
LLEKC & $\mathbf{0 . 2 0}$ & $\mathbf{0 . 1 5}$ & -- \\
\hline OW & $\mathbf{0 . 0 8}$ & $\mathbf{0 . 1 4}$ & $\mathbf{0 . 1 4}$ \\
IAM & $\mathbf{0 . 1 8}$ & $\mathbf{0 . 1 2}$ & $\mathbf{0 . 0 4}$ \\
PLM & $\mathbf{0 . 1 6}$ & $\mathbf{0 . 0 7}$ & $\mathbf{0 . 1 0}$ \\
SDS0.8 & 0.36 & 0.50 & 0.50 \\
SDS1.6 & 0.54 & 0.69 & 0.69 \\
Brij & 0.27 & 0.42 & 0.45 \\
BrijSDS & 0.34 & 0.48 & 0.50 \\
SDSME & $\mathbf{0 . 0 7}$ & $\mathbf{0 . 1 3}$ & $\mathbf{0 . 1 8}$ \\
DGDCChol & $\mathbf{0 . 1 7}$ & $\mathbf{0 . 0 5}$ & $\mathbf{0 . 1 2}$ \\
DGDC & $\mathbf{0 . 2 5}$ & $\mathbf{0 . 1 0}$ & $\mathbf{0 . 1 7}$ \\
PAAU & $\mathbf{0 . 1 8}$ & $\mathbf{0 . 1 1}$ & $\mathbf{0 . 1 5}$ \\
PSUA & $\mathbf{0 . 1 7}$ & $\mathbf{0 . 0 8}$ & $\mathbf{0 . 1 1}$ \\
DHP & 0.32 & 0.42 & 0.41 \\
DHPChol & 0.44 & 0.42 & 0.48 \\
POPCPS & $\mathbf{0 . 1 5}$ & $\mathbf{0 . 1 1}$ & $\mathbf{0 . 1 1}$ \\
\hline & & &
\end{tabular}




\section{Table 4}

553 Composition of the physicochemical systems evaluated in the present work

\begin{tabular}{|c|c|c|c|c|}
\hline Acronym & Technique of separation & Mobile phase & Stationary or Pseudostationary phase & Reference \\
\hline OW & Liquid/liquid partition & Octanol/Water & & [27] \\
\hline IAM & LC & $\mathrm{CH}_{3} \mathrm{CN}$ :phosphate buffer, gradient & IAM & {$[12]$} \\
\hline PLM & LC & Phosphate buffer: $\mathrm{CH}_{3} \mathrm{OH} 8: 2$ & PLM & {$[28]$} \\
\hline LMELC & MELC & Lecithin-based microemulsion & $\mathrm{C} 18$ & Present work \\
\hline SDS0.8 & MELC & SDS, butanol, $0.80 \%$ heptane & $\mathrm{C} 18$ & [29] \\
\hline SDS1.6 & MELC & SDS C18, butanol, $1.60 \%$ heptane & $\mathrm{C} 18$ & [29] \\
\hline Brij & MELC & Brij 35, butanol, heptane & $\mathrm{C} 18$ & [29] \\
\hline BrijSDS & MELC & Brij 35 SDS, butanol, heptane & $\mathrm{C} 18$ & [29] \\
\hline LMEEKC & MEEKC & Phosphate buffer & Lecithin-based microemulsion & Present work \\
\hline SDSME & MEEKC & Phosphate/Borate buffer & SDS, butanol, heptane & {$[30]$} \\
\hline LLEKC & LEKC & Phosphate buffer & Lecithin-based liposomes & Present work \\
\hline DGDCChol & LEKC & $\begin{array}{l}\text { 2-[4-(2-hydroxyethyl)piperazin-1- } \\
\text { yl]ethanesulfonic acid buffer }\end{array}$ & DPPG:DPPC:Chol & [31] \\
\hline DGDC & LEKC & $\begin{array}{l}\text { 2-[4-(2-hydroxyethyl)piperazin-1- } \\
\text { yl]ethanesulfonic acid buffer }\end{array}$ & DPPG:DPPC & [31] \\
\hline PAAU & LEKC & Phosphate/Borate buffer & PAAU & [32] \\
\hline PSUA & LEKC & Phosphate/Borate buffer & PSUA & [32] \\
\hline DHP & VEKC & $\begin{array}{c}\text { Tris(hydroxy- methyl)aminomethane } \\
\text { buffer }\end{array}$ & DHP & [33] \\
\hline DHPChol & VEKC & $\begin{array}{l}\text { Tris(hydroxy- methyl)aminomethane } \\
\text { buffer }\end{array}$ & DHP:Chol & [33] \\
\hline POPC/PS & VEKC & $\begin{array}{l}\text { 2-[4-(2-hydroxyethyl)piperazin-1- } \\
\text { yl]ethanesulfonic acid buffer }\end{array}$ & $\mathrm{POPC} / \mathrm{PS}$ & [34] \\
\hline
\end{tabular}

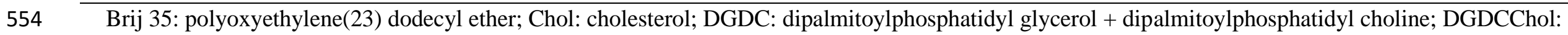


Table 5

$565 d$ distance values between biological and chromatographic systems, according to the SPM coefficients comparison. Values under 0.25 are in bold format

\begin{tabular}{|c|c|c|c|c|}
\hline & System ${ }^{\mathrm{a}}$ & LMELC & LMEEKC & LLEKC \\
\hline BBD & Blood-brain distribution & 0.63 & 0.77 & 0.70 \\
\hline BBP & Blood-brain permeation & 0.58 & 0.73 & 0.73 \\
\hline IA & Intestinal absorption & 0.78 & 0.82 & 0.89 \\
\hline$S P A$ & Skin partition & 0.18 & 0.10 & 0.19 \\
\hline$S P E$ & Skin permeation & 0.21 & 0.23 & 0.34 \\
\hline BBI & Blood-brain partition /in vitro & 0.55 & 0.70 & 0.67 \\
\hline BMI & Blood-muscle partition/in vitro & 0.71 & 0.81 & 0.80 \\
\hline BLII & Blood-liver partition /in vitro & 0.62 & 0.78 & 0.75 \\
\hline$B L U I$ & Blood-lung partition /in vitro & 0.26 & 0.17 & 0.31 \\
\hline BKI & Blood-kidney partition /in vitro & 1.08 & 1.22 & 1.18 \\
\hline BHI & Blood-heart partition /in vitro & 0.56 & 0.60 & 0.59 \\
\hline BFI & Blood-fat partition /in vitro & 0.52 & 0.61 & 0.67 \\
\hline$P B B$ & PAMPA-BBB ${ }^{\mathrm{b}}$ permeability & 0.20 & 0.26 & 0.23 \\
\hline PPO & PAMPA-Po ${ }^{c}$ permeability & 0.34 & 0.50 & 0.49 \\
\hline PDS & PAMPA-DS ${ }^{d}$ permeability & 0.23 & 0.39 & 0.39 \\
\hline $\mathrm{PH}$ & PAMPA-HDM ${ }^{\mathrm{e}}$ permeability & 0.42 & 0.56 & 0.59 \\
\hline PDO & PAMPA-DOPC ${ }^{\mathrm{f}}$ permeability & 0.35 & 0.48 & 0.51 \\
\hline PC & PAMPA-COS ${ }^{\mathrm{g}}$ permeability & 0.62 & 0.76 & 0.78 \\
\hline PP16 & PAMPA-P16 ${ }^{\mathrm{h}}$ permeability & 0.49 & 0.54 & 0.59 \\
\hline
\end{tabular}

\begin{tabular}{|c|c|c|c|c|}
\hline & System $^{\mathrm{i}}$ & LMELC & LMEEKC & LLEKC \\
\hline$R T$ & Rana tadpoles & 0.19 & 0.20 & 0.14 \\
\hline$F M$ & Fathead minnow (Pimephalespromelas) & 0.23 & 0.09 & 0.20 \\
\hline$G P$ & Guppy (Poeciliareticulata) & 0.23 & 0.14 & 0.15 \\
\hline$B G$ & Bluegill (Lepomismacrochirus) & 0.37 & 0.20 & 0.26 \\
\hline GO & Golden orfe (Leuciscusidusmelanotus) & 0.45 & 0.36 & 0.35 \\
\hline GF & Goldfish (Carassiusauratus) & 0.59 & 0.52 & 0.64 \\
\hline MK48 & Medaka high-eyes (Oryziaslatipes) & 0.37 & 0.30 & 0.21 \\
\hline MK96 & Medaka high-eyes (Oryziaslatipes) & 0.46 & 0.38 & 0.35 \\
\hline$D M 24$ & Daphnia magna & 0.29 & 0.16 & 0.27 \\
\hline DM48 & Daphnia magna & 0.23 & 0.13 & 0.22 \\
\hline$C D$ & Ceriodaphniadubia & 0.22 & 0.20 & 0.30 \\
\hline$D P$ & Daphnia pulex & 0.32 & 0.20 & 0.29 \\
\hline$T P$ & Tetrahymena pyriformis & 0.25 & 0.15 & 0.22 \\
\hline$S A$ & Spirostomumambiguum & 0.35 & 0.21 & 0.32 \\
\hline ES & Entosiphonsulcantum & 0.47 & 0.35 & 0.35 \\
\hline UP & Uronemaparduczi & 0.70 & 0.66 & 0.59 \\
\hline $\mathrm{CP}$ & Chilomonas paramecium & 0.43 & 0.38 & 0.32 \\
\hline PP & Pseudomonas putida & 0.32 & 0.33 & 0.30 \\
\hline PG & Porphyromonasgingivalis & 0.39 & 0.34 & 0.22 \\
\hline$S R$ & Selenomonasartemidis & 0.39 & 0.26 & 0.20 \\
\hline SS & Streptococcus sobrinus & 0.39 & 0.34 & 0.24 \\
\hline $\mathrm{AP}$ & Alga cell permeation & 0.95 & 1.07 & 1.08 \\
\hline$S W P$ & Soil-water sorption & 0.26 & 0.25 & 0.26 \\
\hline
\end{tabular}


$571 \quad{ }^{a}$ Systems of pharmaceutical interest; ${ }^{b}$ PAMPA: parallel artificial membrane permeability assays / BBB:

572 blood brain barrier; ${ }^{\mathrm{c}}$ Po: intrinsic permeability; ${ }^{\mathrm{d}}$ DS: double-sink permeability measurement; ${ }^{\mathrm{e}} \mathrm{HDM}$ : $\mathrm{n}$ -

573 hexadecane PAMPA model; ${ }^{\mathrm{f}}$ DOPC: dioleyoylphosphatidylcholine in n-dodecane PAMPA model; ${ }^{\mathrm{g}}$ COS:

574 cosolvent PAMPA method; ${ }^{\mathrm{h}} \mathrm{P} 16$ : hexadecane membrane system, ${ }^{\mathrm{i}}$ Systems of environmental interest (the 575 toxicity to several aquatic species, the alga-cell permeation and the soil-water sorption)

576 


\section{Table 6}

578 Contributions that determine the overall variance $\left(\mathrm{SD}_{\text {corr cal }}{ }^{2}\right)$ in the correlations between skin partition 579 data and chromatographic data of the lecithin-based systems

580

\begin{tabular}{lcccccc}
\multicolumn{2}{c}{$\mathrm{q}_{\text {cal }}$} & $\mathrm{p}_{\text {cal }}$ & $\left(\mathrm{p}_{\text {cal }} \mathrm{SD}_{\text {chrom }}\right)^{2}$ & $\mathrm{n}_{\text {chrom }}$ & $\mathrm{SD}_{\mathrm{d}}{ }^{2}$ & $\mathrm{SD}_{\text {corr cal }}{ }^{2}$ \\
\hline \multicolumn{2}{c}{ Skin partition } \\
$\left(\mathrm{SD}_{\text {bio }}{ }^{2}=\right.$ & $\left.0.047, \mathrm{n}_{\text {bio }}=45\right)$ & & & & \\
\hline LMELC & 0.261 & 0.850 & 0.004 & 40 & 0.028 & 0.079 \\
LMEEKC & 1.747 & 0.563 & 0.005 & 47 & 0.009 & 0.062 \\
LLEKC & 1.505 & 0.687 & 0.007 & 46 & 0.013 & 0.067 \\
\hline
\end{tabular}

581 
583 Experimental $\log \mathrm{K}_{\mathrm{SC}}$ values from the literature [22] and experimental $\log k$ values 584 measured in this work by LLEKC and LMEEKC for different solutes

\begin{tabular}{|c|c|c|c|}
\hline Solute & $\log \mathrm{K}_{\mathrm{SC}}$ & $\log k_{L L E K C}$ & $\log k_{L M E E K C}$ \\
\hline 2-Nitro- $p$-phenylenediamine & 0.57 & -0.89 & -1.25 \\
\hline Cortexolone & 0.86 & 0.13 & -0.54 \\
\hline Cortisone acetate & 0.80 & 0.29 & -0.72 \\
\hline Diazepam & 1.25 & 0.64 & 0.07 \\
\hline Estrone & 1.13 & 1.05 & 0.42 \\
\hline Hydroxyprogesterone & 1.08 & 0.86 & -0.10 \\
\hline$m$-Cresol & 1.06 & -0.20 & -0.61 \\
\hline Nicotinamide & 0.07 & - & -1.32 \\
\hline$o$-Phenylenediamine & 0.37 & -1.18 & -1.26 \\
\hline$p$-Bromophenol & 1.46 & 0.10 & 0.11 \\
\hline Testosterone & 1.40 & 0.45 & -0.11 \\
\hline Progesterone & 1.75 & 1.40 & 0.57 \\
\hline p-Chlorophenol & 1.34 & 0.10 & -0.04 \\
\hline 2-Naphthol & 1.55 & 0.73 & 0.30 \\
\hline Benzene & 1.48 & -0.10 & -0.41 \\
\hline Corticosterone & 0.74 & 0.10 & -0.61 \\
\hline Cortisone & 0.50 & -0.38 & -1.03 \\
\hline Estradiol & 1.13 & 1.15 & 0.37 \\
\hline Estriol & 0.86 & - & -0.74 \\
\hline Hydrocortisone & 0.44 & -0.31 & -0.90 \\
\hline$p$-Cresol & 1.06 & 0.78 & -0.56 \\
\hline Phenol & 0.76 & -0.51 & -0.92 \\
\hline Pregnenolone & 1.70 & -1.09 & - \\
\hline Resorcinol & 0.29 & -0.56 & -1.11 \\
\hline Thymol & 1.89 & 0.99 & 0.44 \\
\hline
\end{tabular}


$589 \quad$ Figure 1

590 Comparison of the normalized SPM properties of the three lecithin-based systems 591 (LMELC: $\boldsymbol{\Delta}$; LMEEKC: ; LLEKC: $\mathbf{})$.

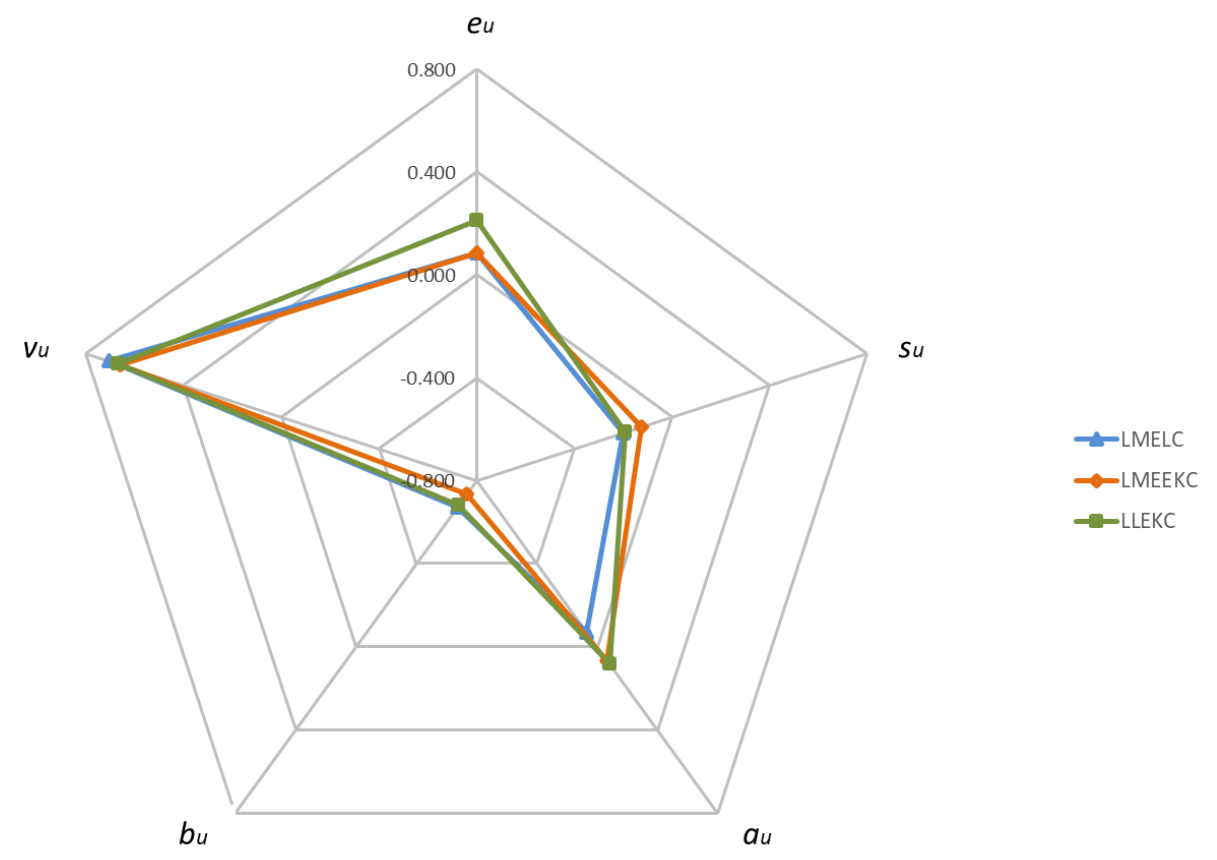

592

593

594 
595 Figure 2

596 Comparison of the similarity between the three lecithin-based systems and other 597 physicochemical systems

598 a) Dendrogram plot of the selected physicochemical systems, together with the $599 \quad$ lecithin-based ones.

600 b) PCA scores plot of the physicochemical systems (o) and the lecithin systems 601 evaluated in this work (symbols as in Figure 1). 
a)

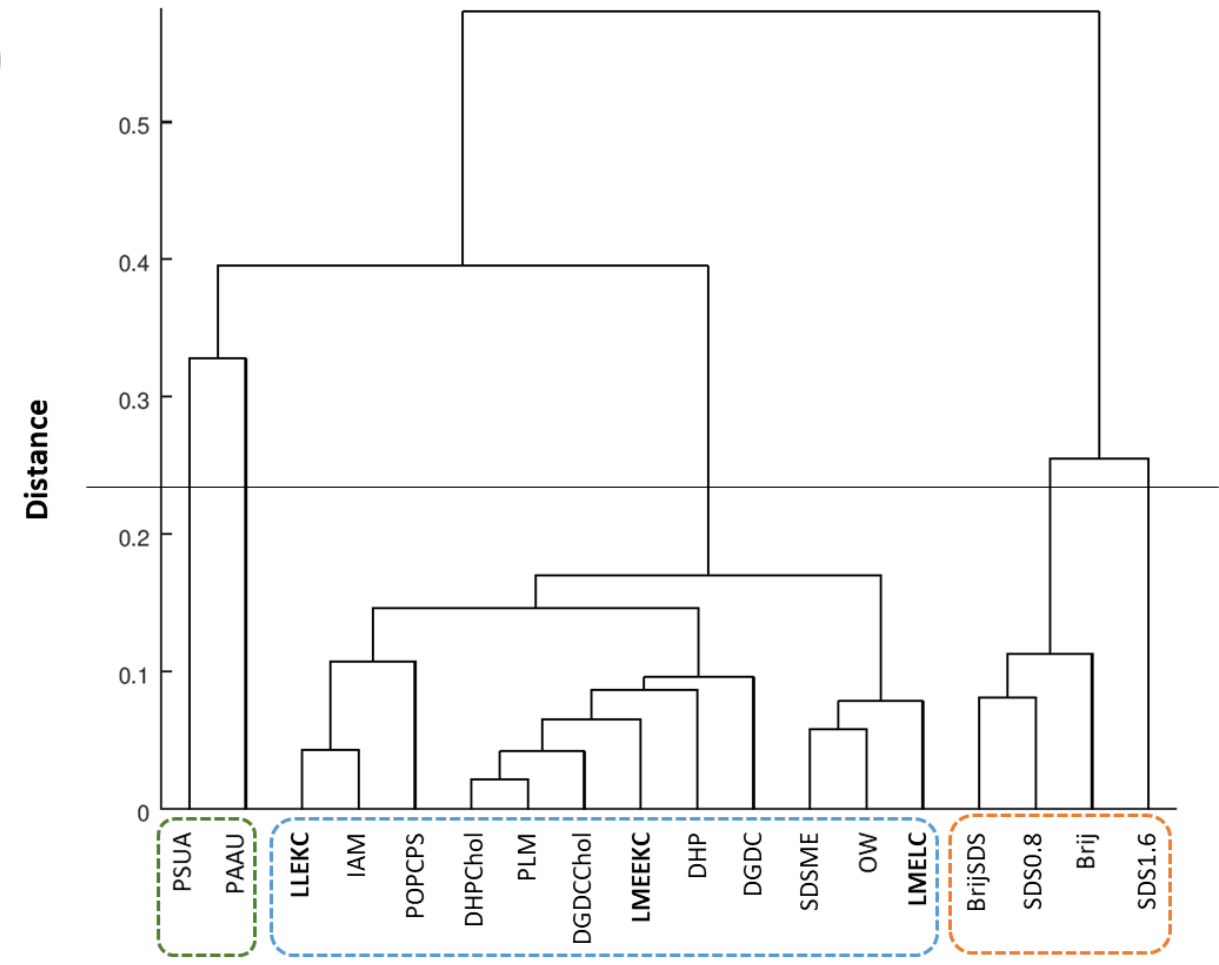

b)

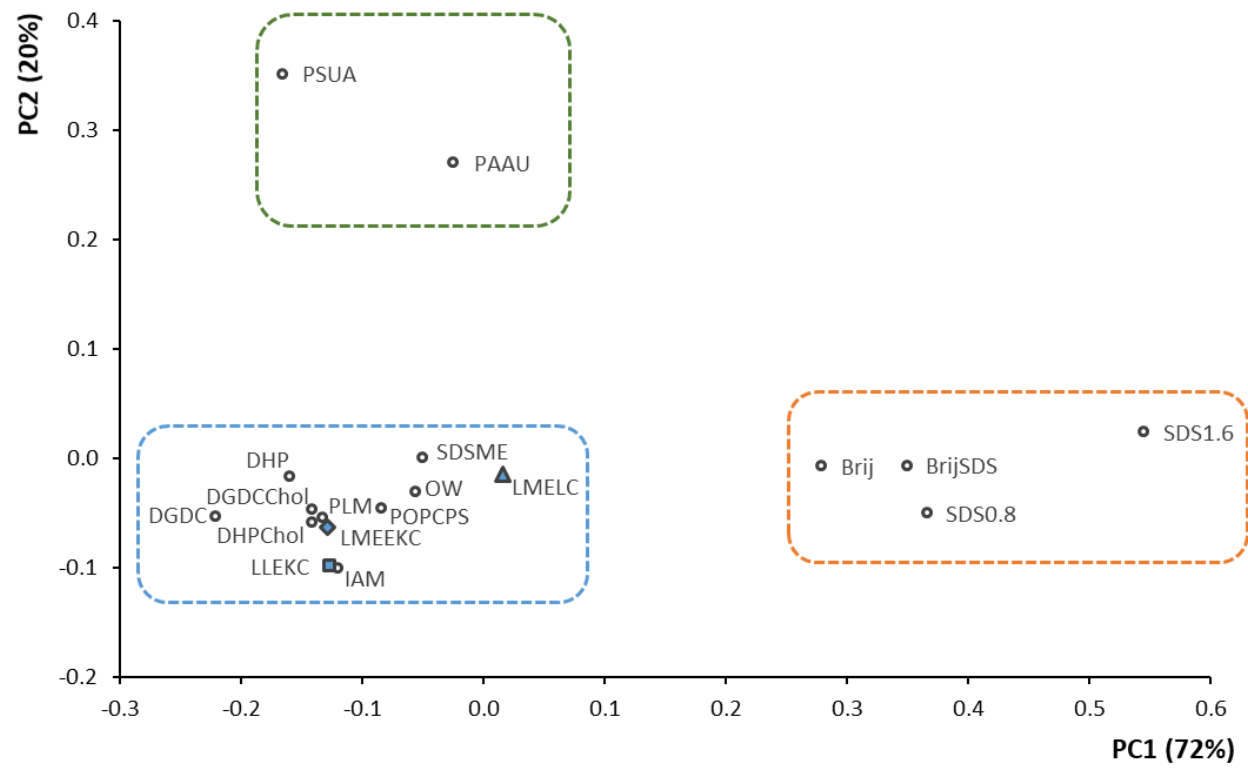

603

604 
605 Figure 3

606 Comparison of the similarity between the three lecithin-based systems and biological 607 systems

608 a) Dendrogram plot of the selected biological systems, together with the lecithin609 based ones.

610 b) PCA scores plot of the biological systems (o) and the lecithin systems evaluated 611 in this work (symbols as in Figure 1). 
a)

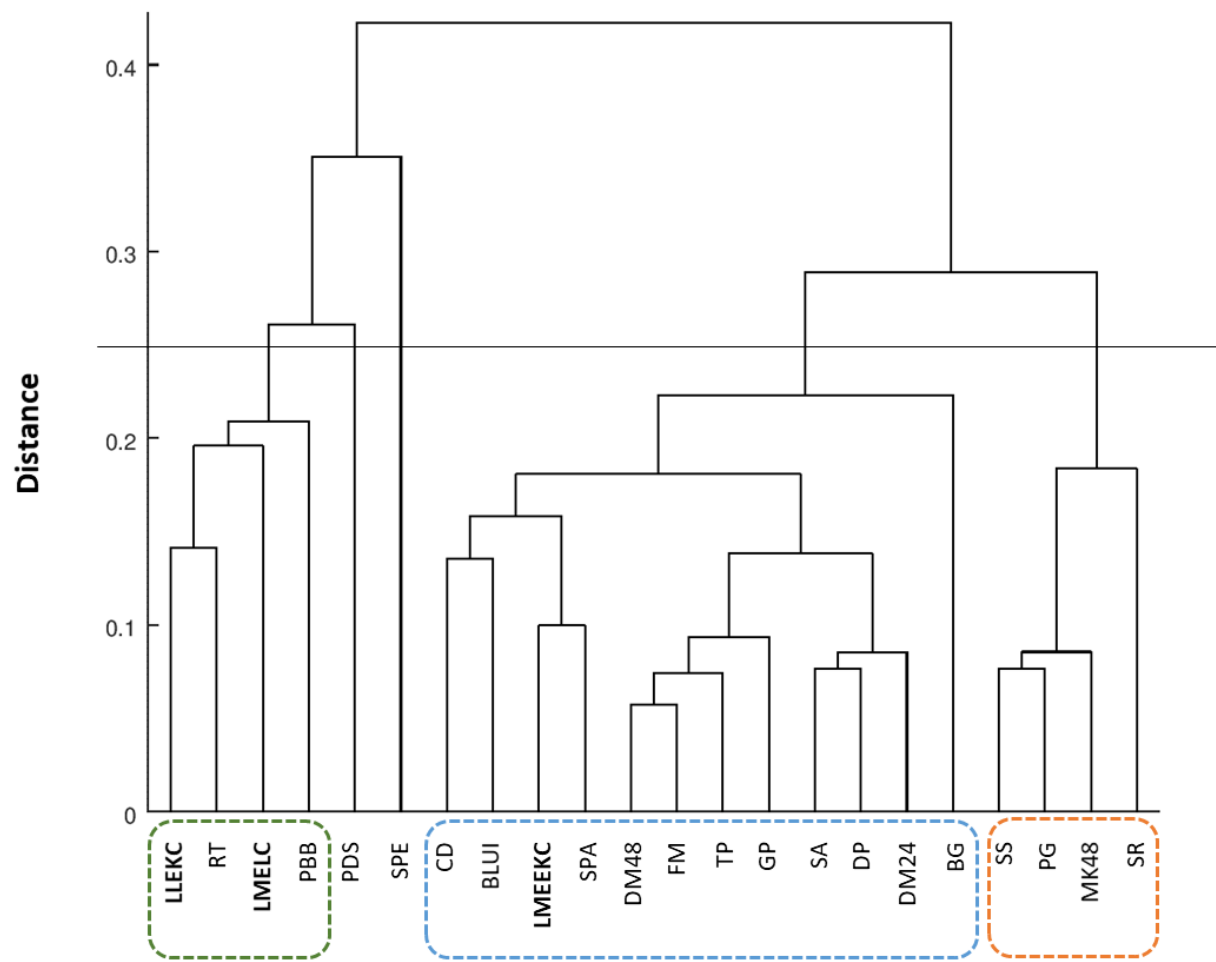

b)

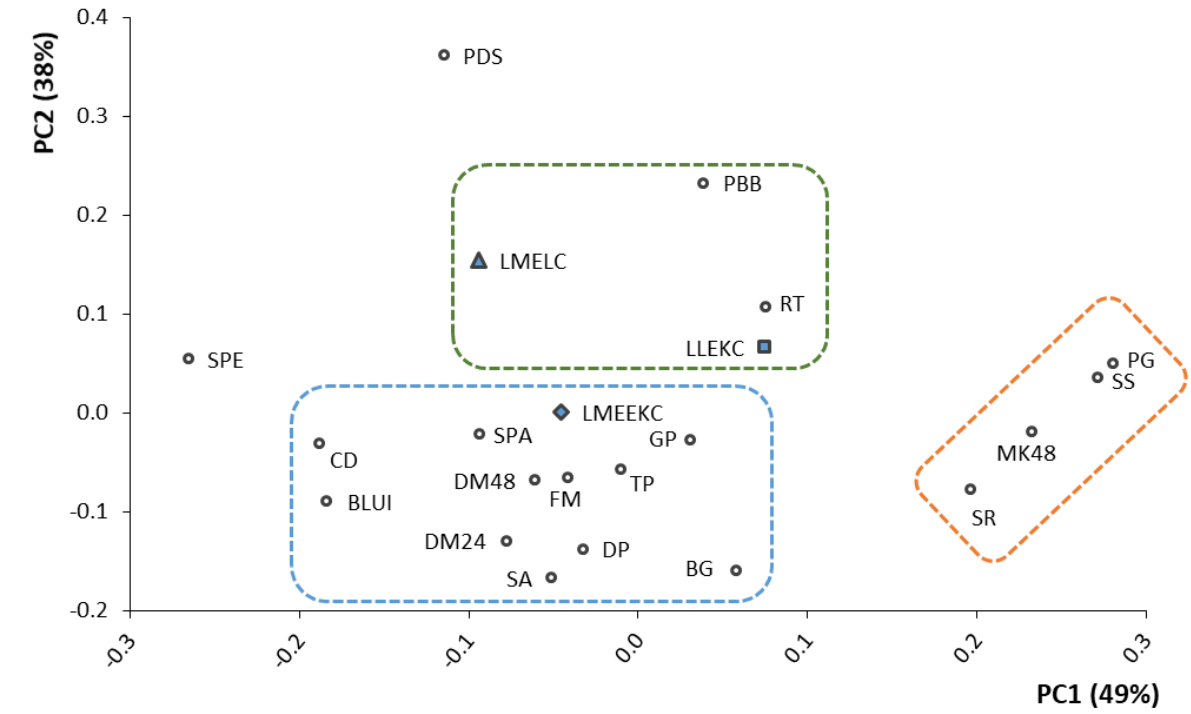


614 Figure 4

615 Correlation between skin partition and retention in the LMEEKC system. The solid line 616 is the plot of the regression equation.

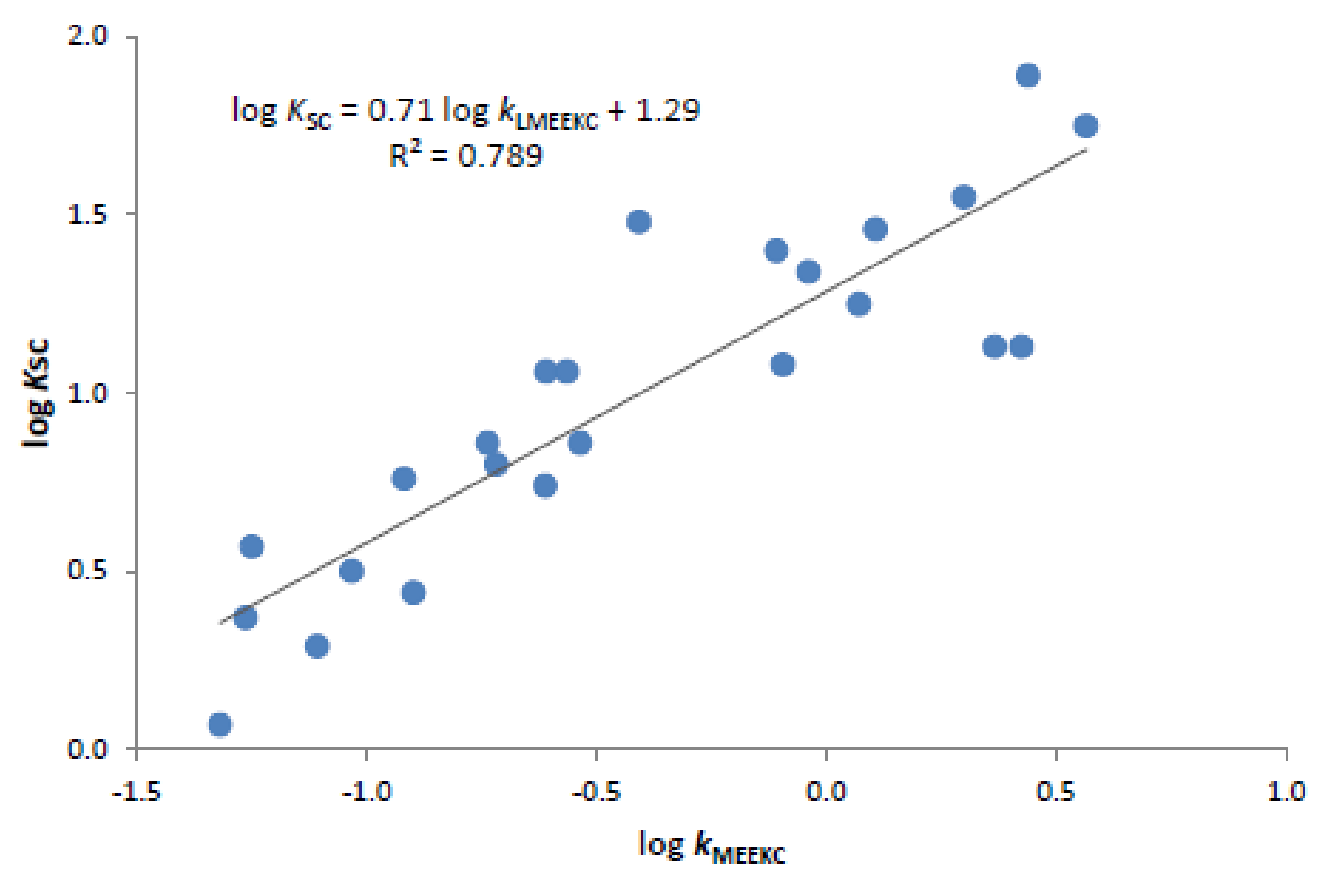

617 